\title{
Unmet support needs and distress among women with a BRCA1/2 mutation
}

Ashley Farrelly ${ }^{1}$, Victoria White ${ }^{1}$, Bettina Meiser ${ }^{2}$, Michael Jefford $^{1,3,4}$, Mary-Anne Young ${ }^{3}$,

Sandra leropoli ${ }^{5}$, Ingrid Winship ${ }^{4,6}$, Jessica Duffy $^{7}$

${ }^{1}$ Cancer Council Victoria, Melbourne, Victoria, Australia

${ }^{2}$ University of New South Wales, Sydney, New South Wales, Australia

${ }^{3}$ Peter MacCallum Cancer Centre, Melbourne, Victoria, Australia

${ }^{4}$ University of Melbourne, Melbourne, Victoria, Australia

${ }^{5}$ Early in Life Mental Health services, Southern Health, Clayton, Victoria, Australia

${ }^{6}$ The Royal Melbourne Hospital, Melbourne, Victoria, Australia

${ }^{7}$ Prince of Wales Hospital, Sydney, New South Wales, Australia

Corresponding author at: Centre for Behavioral Research in Cancer, Cancer Council

Victoria, 1 Rathdowne Street, Carlton, Victoria, 3000, Australia

T: +61 396355429 F: +6139635 5380 Email: Ashley.Farrelly@cancervic.org.au

Word Count: 4047 words (excluding title page, abstract, tables and references)

Abstract: 252 Words 


\section{Abstract}

Distress levels among female $B R C A 1 / 2$ mutation carriers can be similar to levels found among breast cancer patients. While psychological distress has been associated with unmet needs among cancer patients no study has examined this among BRCA1/2 mutation carriers. The objectives of this study were to: (1) describe the unmet support needs of women with a known $B R C A 1 / 2$ mutation, (2) determine how unmet needs are related to psychological distress, and (3) identify variables that predict level of unmet need and distress. Female BRCA1/2 mutation carriers were identified through Familial Cancer Centers in 3 Australian states. 279 participants completed surveys assessing need for help on 16 information and support items. The Impact of Events Scale assessed genetic test related distress. Participants reported an average of $5.4(S D=4.9)$ moderate to very high unmet needs. $21 \%$ had scores indicating moderate distress, and $13 \%$ indicating severe distress. Younger age $(t=-3.34 ; p<0.01)$, not having someone to confide in about the gene mutation $(t=2.57 ; p=0.01)$ and shorter time since notification of mutation status $(t=-2.49 ; p=0.01)$ were associated with higher unmet need scores in linear regression analyses. Greater number of unmet needs was associated with a greater likelihood of moderate to severe levels of distress (OR 1.19; $p<0.01)$ in logistic regression analyses. Identifying appropriate interventions that target unmet needs among younger women and those with no confidante may help to reduce distress. Interventions that provide an opportunity for women to confide in someone, such as Peer support programs, may be one way of meeting the emotional needs of this population.

Keywords: BRCA1/2; Psychological distress; Unmet needs; breast/ovarian cancer; Impact of Events Scale 


\section{Introduction}

Women who carry a mutation in one of the breast/ovarian cancer genes, $B R C A 1$ or $B R C A 2$, face up to a $65 \%$ risk of developing breast cancer and up to a $39 \%$ risk of developing ovarian cancer by the age of 70 [1]. There is evidence that risk-reducing bilateral mastectomy (BM) decreases the risk of breast cancer by up to 95\% [2], and that riskreducing bilateral salpingo-oophorectomy (BSO) reduces the risk of ovarian cancer by approximately $90 \%$, and the risk of breast cancer by approximately $50 \%$ [3]. While monitoring by mammography or breast MRI is an effective means of detecting breast cancer early, currently no monitoring strategy is effective for the early detection of ovarian cancer [46]. As a result, women found to carry a $B R C A 1 / 2$ mutation are faced with complex decisions about how to manage their cancer risk, as well as determining how best to communicate this risk information to family members.

Many of the risk management strategies offered to women can have negative consequences for both immediate and long-term quality of life. While distress levels for people testing negative for a cancer gene mutation decrease substantially after learning their test results, there is evidence that distress levels for those found to be carriers remain elevated $[7,8]$. Several studies have shown that distress levels among $B R C A 1 / 2$ mutation carriers are higher than those found in the general population, and are similar to levels found amongst women with breast cancer within a year of diagnosis [8,7,9-12] . One longitudinal study found that some women who have undergone BRCA1/2 genetic testing (and have received their test result) experience long term psychological distress [13].

Quantitative research examining potential risk factors for distress among women with the $B R C A 1 / 2$ mutation is limited. One study investigating this issue found that distress levels were predicted by high pre-test distress about hereditary cancer, having young children and having a relative who had died from cancer [13]. There is evidence from cancer patients that psychological distress is positively associated with levels of unmet needs [14]. Unmet needs are those issues that people perceive a need for help with, and for cancer patients these 
domains include assistance with daily living activities, physical activities, psychological wellbeing and obtaining treatment or prevention information $[15,16]$. Little is known about the association between unmet needs and psychological distress among women with a $B R C A 1 / 2$ mutation.

Much of the work examining the unmet needs of women with a $B R C A 1 / 2$ mutation has been qualitative in nature $[17,18]$. The need for more information and access to support sources were commonly identified themes in studies from the United States [18] and the United Kingdom [17]. The information needs identified in these studies included: obtaining more information about their risk status, and gaining a better understanding of the guidelines for cancer screening and prevention. Women in these studies also expressed a need for support groups and/or support networks other than family/friends and genetic services.

A quantitative study of 156 cancer gene mutation carriers in South Australia reported similar unmet needs [19]. Twenty-six per cent of this sample wanted more information on how to reduce their cancer risk, mechanisms to reduce feelings of isolation and to find others who understood their situation. Comparable levels of information needs have been found among Canadian women with a confirmed $B R C A 1 / 2$ mutation; where $21 \%$ wanted more information, particularly more information on risk-reducing surgery options [20].

Factors that may influence $B R C A 1 / 2$ mutation carriers' levels of unmet needs are not well understood. We could find only one study that has examined this issue [20], which found that $B R C A 1 / 2$ mutation carriers with cancer had a greater need for information than those without cancer. Studies of cancer patients report that smaller networks of social support, geographical isolation and lower income correlate with higher levels of unmet needs [15,21-23]. However, the relationship between unmet needs and age is not clear. Some studies report unmet needs increase with age, while others report that needs decrease with age or exhibit a non-linear relationship [15,24]. It is not clear whether these associations would be found in a population like $B R C A 1 / 2$ mutation carriers who may or may not have had a diagnosis of cancer. 
The objectives of this study were to: (1) describe the unmet support needs of women with a known BRCA1/2 mutation, (2) determine how unmet needs are related to psychological distress, and (3) identify variables that predict level of unmet need and distress.

\section{Methods}

\subsection{Recruitment of participants}

Participants were recruited as part of an ongoing randomized controlled trial testing the effectiveness of a telephone based peer support program for women with a $B R C A 1 / 2$ mutation. Participants were identified through eight Familial Cancer Centers (FCC) in three Australian states (Victoria, New South Wales and South Australia). Women aged 18 and over who had been identified as carrying a BRCA1/2 mutation and who had completed all their standard genetic counseling sessions at an FCC were eligible for study participation. The FCC wrote to women to inform them of the study and women interested in learning more about the study returned a consent form to the researchers. The researchers then contacted interested women by mail, provided them with further information about the study, and obtained signed consent regarding study participation.

Participants completed a baseline survey after enrolling in the study and prior to randomization.

As family members often attend the same FCC it was not unusual for participants from the same family to enroll in the study.

\subsection{Measures}

\subsubsection{Independent variables}

Sociodemographic variables collected included: age, whether the participant had children, level of education (categorized as (i) secondary school only or (ii) certificate/diploma or university degree) and marital status (categorized as (i) married, (ii) in a relationship (including those cohabitating and not), and (iii) single, divorced, or widowed).

Participants reported on whether they had a breast or ovarian cancer diagnosis and whether they had undergone any risk-reducing surgeries, specifically BM or BSO. Use of 
risk-reducing surgery was coded into four groups: no risk-reducing surgery, BM only, BSO only or both surgeries. BSO only was used as the reference category in analysis as it is the most commonly recommended risk-reducing surgery option for women with a $B R C A 1 / 2$ mutation [25].

Time since being notified of a positive test result (in years), and number of first- or second-degree relatives diagnosed with breast and/or ovarian cancer were also collected. Participants indicated whether they had anyone to confide in about testing positive for a $B R C A 1 / 2$ mutation (yes or no).

\subsubsection{Outcome variables}

Level of unmet need was assessed using a modified version of a 9-item scale created for women with a high risk of breast cancer [16]. The original scale was developed following the approach taken with unmet need scales for cancer patients [26,27]. The modified scale consists of 16 items covering information needs about risk-reducing surgery and screening, communication with family members, social support and psychological needs (items shown in Table 2). Items added to the original scale covered additional issues identified in the literature as relevant for BRCA carriers [17-19]. These items included: level of need for talking to family members/children about the mutation, deciding how to best manage one's increased cancer risk, obtaining information about options to manage one's cancer risk, dealing with feelings of isolation, finding someone who understands one's situation and dealing with insurance issues that arise from carrying the mutation. For each item, respondents reported their level of need in the past month on a 5-point scale indicating no need, low need, moderate need, high need, or very high need. Items were coded as either no need or any need (low to very high need inclusive) and responses summed to provide an indication of the number of any needs women had. Cronbach alpha reliability for the 16-item scale used in this study was high $(\alpha=0.93)$.

Level of distress was measured using the 15-item Impact of Events Scale (IES), which assesses the experience of stress in relation to a specific life event (in this case the stress of a positive genetic test result). Responses are made on a 4-point Likert scale and 
scores range from 0 to 75 . Scores between 26 and 43 indicate moderate distress, while scores of 44 and above indicate severe distress [28-30]. The IES has two subscales that measure intrusive thoughts and feelings, and avoidance of certain thoughts, feelings or situations. The IES has been used frequently to assess distress among those testing positive for a cancer gene mutation and has been found to have good internal consistency among this group [31].

The variables analyzed in this study are a subset of all variables collected in the baseline survey for the larger study.

\subsection{Analysis}

Descriptive statistics, including frequencies and means, were produced for the sample. Response frequencies were detailed for each item on the unmet needs scale.

Univariate associations between the independent variables and summed unmet needs score were examined using simple regression. The IES variable was dichotomized using the cut off score of 26 and higher for moderate to severe distress, as it was not normally distributed and log transformation of the data did not result in normality. Univariate associations between independent variables and the dichotomized IES variable were examined using logistic regression.

Multivariable linear and logistic regression were used to assess the independent contribution of variables to the summed unmet needs score and the dichotomized IES scores respectively. Saturated models, with all independent variables entered, are presented. Multicollinearity between the independent variables in the model was also considered. All tests were two tailed and associations are considered statistically significant if $p<0.05$. Correlation of responses between family members was adjusted for in analyses using the cluster option in Stata [32] and robust standard errors were produced using the Hubert-White sandwich estimator.

All statistical analyses were carried out using STATA version 11.2 and SPSS version 18.0.0 (for descriptive statistics).

\subsection{Ethical Approval}


Ethical approval for this study was obtained from the Human Research Ethics Committee of the Cancer Council Victoria, as well as the ethics committees responsible for each FCC.

\section{Results}

To date, 669 women have been approached by the FCCs to participate in the study, and of these 299 have consented (response rate of 45\%). Data is from 279 participants who had consented to study participation and had completed the baseline survey at the time of analysis. Ninety-three participants (33\%) had a family member in the study.

Participants' average age was 46 years (SD: 13.9) and 44\% $(n=124)$ had a previous diagnosis of breast cancer (37\%), ovarian cancer (6\%), or both (1\%). Mean time since notification of carrier status was 1.7 years $(S D=1.5)$ (Table 1$)$.

There were no significant differences in age, education level, cancer diagnosis and history of risk-reducing surgery between women recruited from the different FCCs.

\subsection{Distress}

The median distress score for participants was 15.0 (range 0-70). Median scores on the intrusion and avoidance subscales were 7.0 (range 0-35) and 8.0 (range 0-40) respectively. Twenty-one percent $(n=57)$ of participants had scores indicating moderate distress, and 13\% ( $n=35)$ had scores indicating severe distress.

\subsection{Unmet Needs}

Only $9 \%(n=25)$ of participants reported having no unmet needs. On average, participants reported $9.2(S D=5.3)$ unmet needs (low to very high inclusive) and 5.4 $(S D=4.9)$ moderate to very high unmet needs. $33 \%(n=91)$ of participants reported having 15 moderate to very high needs, $24 \%(n=66)$ reported $6-10$ moderate to very high needs and $19 \%(n=53)$ reported $11-16$ moderate to very high needs.

The most commonly endorsed moderate to very high needs were: "dealing with uncertainty about the future" (46\%), "dealing with fears about developing cancer" (42\%), and "dealing with the impact a faulty gene has had on your family" (41\%) (Table 2). While the 
items: "dealing with insurance issues" (22\%) and "dealing with feelings of isolation" $(22 \%)$ were least frequently endorsed, one in five women reported these needs

Of women with children, $21 \%(n=46)$ stated a high to very high need for "talking to your children about their cancer risk".

\subsection{Univariate and mulitvariable associations with unmet needs}

Mean number of unmet needs for different levels of categorical independent variables and correlation between number of unmet needs and linear independent variables are shown in Table 1. Table 3 shows univariate and multivariable associations with the number of unmet needs. For univariate analyses, a higher number of unmet needs was significantly associated with shorter time since notification of mutation status $(\mathrm{t}=-2.21$, $\mathrm{p}=0.03)$, and younger age $(\mathrm{t}=-3.04, \mathrm{p}<0.01)$. Participants who felt they had someone to confide in about testing positive for the mutation had a significantly lower number of unmet needs than those who did not report a confidante $(t=-2.16, p=0.03)$.

In regression analyses, age, having someone to confide in and time since notification of mutation status remained significantly associated with level of unmet need (Table 3). However only $10 \%$ of the variance in number of unmet needs was explained by these associations.

\subsection{Bivariate and multivariable associations with test-related distress (IES)}

Table 4 shows univariate and multivariable associations with test-related distress.

In univariate analyses, type of risk-reducing surgery was significantly associated with distress. Women who chose not to have risk-reducing surgery $(\mathrm{OR}=2.31,95 \% \mathrm{Cl} 1.27-4.22)$, and women who had undergone BM only $(\mathrm{OR}=4.06,95 \% \mathrm{Cl} 1.57-10.51), \mathrm{p}<0.01)$ had a greater likelihood of moderate to severe distress compared to women who had a BSO only. Women having both surgeries were not significantly different from women having BSO only on moderate to severe distress..

Having someone to confide in was also significantly related to distress scores (Table 3). Participants who had someone to confide in about testing positive for the gene mutation had lower distress scores than women who did not have a confidante. 
Younger women had higher distress scores than older women $(\mathrm{OR}=0.9795 \% \mathrm{Cl}$ 0.95-0.99). Marital status was significantly related to distress, with participants who were in a relationship but not married being more likely to have moderate to severe distress scores than married participants (Table 4); no significant differences were observed with women who were single, divorved or widowed.

Unmet needs and distress scores were significantly associated $(p<0.01)$. Women with moderate to severe distress scores reported on average four more unmet needs than women with no or low distress (Table 1).

In multivariable logistic regression analyses, not having a confidante $(p=0.01)$, being in a relationship but not married $(p<0.01)$ and having no risk-reducing surgery $(p=0.03)$ or having only BM $(p<0.01)$ were associated with an increased likelihood of experiencing moderate to severe distress (Table 4). In addition, a greater number of unmet needs was associated with a greater likelihood of having moderate to severe levels of distress $(p<0.01)$. Logistic regression analyses were re-run using severe distress (IES scores $\geq 44$ ) as an outcome measure. A greater number of unmet needs $(p<0.01)$ and having no one to confide in ( $p=0.01)$ significantly increased the likelihood of severe distress (data not shown).

\section{Discussion and Conclusion}

\subsection{Discussion}

\subsubsection{Summary of findings}

This study is one of the largest conducted to date to quantitatively examine the unmet supportive care needs and distress levels of women with a BRCA1/2 mutation. The study found a high level of unmet support needs among participants, with close to half of the sample reporting at least six moderate to very high unmet needs, while only $9 \%$ of the sample had no unmet needs. Predictors of higher levels of unmet needs were shorter time since finding out about mutation status and younger age, and a key finding of this study is the importance of having someone to confide in. While only $7 \%$ of women reported that they did not have anyone in whom to confide this group of women was at substantially greater 
risk of having unmet support needs and were over four times more likely to experience moderate to severe distress.

This study also suggests the importance of addressing unmet needs, as higher levels of unmet needs were associated with higher levels of distress (though because of the crosssectional nature of the research we cannot ascertain causality). While on average, distress levels of study participants were normal, it is of some concern that a third of our participants reported moderate to severe distress scores.

\subsubsection{The unmet needs of women with a BRCA1/2 mutation.}

The most common unmet needs among participants were dealing with uncertainty about the future, and dealing with fears about developing cancer. Our study also found that dealing with feelings of isolation was one of the least reported needs by participants. This finding may reflect the fact that almost all participants stated that they have someone to confide in about having the gene mutation.

Our findings contrast with the results of Thewes, et al. [16] who looked at the unmet needs of women with a family history of breast cancer but who had not been diagnosed with cancer. Additionally, none of the women in that study had been identified as having the $B R C A 1 / 2$ mutation. That study found informational needs to be the most commonly endorsed. In our study these needs were some of the least reported. It is possible that the information needs of women with the $B R C A 1 / 2$ mutation may be addressed through the genetic counseling process. It is also possible that some of the information needs of women with a strong family history of breast cancer relate to finding out their mutation status. As women in our study knew their mutation status, their needs in this area may have been reduced.

Our study found that unmet needs were higher among younger women. Some studies of breast cancer survivors have reported a similar finding, and have suggested that the needs of young women often center on fertility and concerns about premature menopause $[33,34]$. Similar concerns may be found among young women with a $B R C A 1 / 2$ 
mutation, as these women are faced with making complex decisions about risk-reducing surgery that can have both gynecological and reproductive consequences.

Many studies have shown that social support enhances psychological wellbeing, including research showing a positive effect of peer support for people with cancer $[35,36]$. Our finding that having someone to confide in was associated with fewer unmet needs underscores the importance of supportive relationships. Previous work with women with a BRCA1/2 mutation [18] and those with a high risk of cancer [17] also suggest that networks of support are a potentially important way of meeting the emotional needs of women.

\subsubsection{How feelings of unmet needs are related to test-related distress}

Average test-related distress scores among participants in our study were similar to those identified in other samples of women tested for $B R C A 1 / 2$ mutations $[8,37,38]$. However, despite the relatively low average distress scores for our sample, $34 \%$ of participants had moderate to severe levels of distress.

Higher levels of unmet needs, the lack of having someone in whom to confide, being in a relationship (but not married) and not having had risk-reducing surgery, or having had BM only, were associated with moderate to severe levels of distress. Few studies have examined the role of a confidante in reducing distress among $B R C A 1 / 2$ mutation carriers. $\mathrm{A}$ study by den Heijer, et al. (2011) examined the role of social support and use of a confidante or significant other among women with a high risk for familiar cancer, and found that greater social support and having a confidante was associated with lower distress [39].

We found that participants in a relationship (but not married) had higher levels of distress than those who were married, single, divorced or widowed. While our data cannot be used to explain this relationship, other work has shown that women who have a $B R C A 1 / 2$ mutation experience stress and anxiety when navigating the early stages of relationships, facing issues such as whether and what to tell their partners about their mutation status and how to lead potential discussions of future childbearing [40]. For participants in our study it may be that those who are in a relationship (and not married) but have not yet explicitly disclosed expectations about having children, face greater uncertainty and distress about 
these issues compared to those who are married and are thus likely to have established roles and expectations for their relationship, or those who are single and have not yet had to address these issues. As there is little work in this area future studies examining the influence of relationship status and associated factors on levels of distress among $B R C A 1 / 2$ carriers are needed.

We also found that women who had not had risk-reducing surgery or who had a BM only had higher distress scores than those who underwent a BSO only. The latter association may be unexpected. While several other studies have reported decreases in distress levels after BSO $[30,41]$, one study [42] found that women opting for BM had greater reductions in distress levels than women choosing BSO 12 months after surgery. However, as women choosing to have BM had higher distress levels prior to surgery than those choosing BSO the role of surgery type in influencing distress levels is unclear.

$\mathrm{BSO}$ is the most commonly recommended risk-reducing surgery for women with a $B R C A 1 / 2$ mutation, and it is generally recommended that women undergo this surgery as soon as possible after childbearing is complete [25]. It is possible that women in our sample who have chosen BM only are experiencing a tension between wanting to control their cancer risk (through a BSO) and wanting to begin or continue childbearing. In contrast, women who have chosen an BSO may feel that they have taken adequate measures to address their cancer risk.

Higher levels of unmet needs and not having someone in whom to confide continued to be associated with a greater likelihood of severe distress scores (no other variables were significant at $p<0.05)$. It is likely that these two variables are key factors that help to explain the experience of test-related distress among BRCA mutation carriers. Their role in predicting not only moderate, but severe distress scores further highlights the need to address elevated levels of unmet need and lack of social support when identified.

\subsubsection{Limitations}

There are some limitations to this study. First, as women in this study were drawn from a larger study examining the impact of a peer support program it is possible that the 
women in our sample have higher needs than the overall population of $B R C A 1 / 2$ carriers. However, we note that only $27 \%$ of women in the larger study indicate that they are interested in peer support or talking to other women, suggesting that the study is not only attracting women with unmet peer support needs. The wide range of needs identified among our sample further supports this. However, it is possible that the needs reported in our study are not reflective of the level found or the type of needs experienced by all women with a BRCA1/2 mutation.

Additionally, it is worth noting that though we found no differences in level of unmet needs between those with a previous cancer diagnosis and those without, this may be a result of the fact that the unmet needs scale focused on needs related to the $B R C A 1 / 2$ mutation and that these two groups differ in other areas of need that have not been assessed, but may be important for women with a cancer diagnosis. These areas may include assistance with daily living and physical effects, along with distinct needs across the diagnosis, treatment and survivorship phases.

It would have been useful to include questions assessing childbearing intentions and unmet needs relating to childbearing issues (e.g. making decisions, discussing issue with partner, etc.). We used an unmet needs scale adopted from work with women at high risk for breast cancer as no scale exists specifically for women with a $B R C A 1 / 2$ mutation. Future work in this area may benefit from the development of a specific unmet need scale for this population that addresses the full spectrum of possible needs.

\subsection{Conclusion}

Many women with a known $B R C A 1 / 2$ mutation have supportive care needs that are not currently being addressed through standard genetic counseling sessions. This is concerning as the results of this study suggest that those with high unmet needs also have high test-related distress scores.

\subsection{Practice Implications}

Findings from this study suggest that FCCs and Genetic Services could consider follow-up of gene mutation carriers with particular focus on screening for unmet supportive 
care needs. Our data suggest that potentially at risk women include those of younger age, those who have been notified of their mutation status more recently, and those who do not feel they have someone in whom to confide about their mutation status. Identifying appropriate interventions that target commonly identified unmet needs, and determining what extra services are needed for this potentially vulnerable group may be worthwhile.

\section{Acknowledgements}

This research was funded by The National Breast Cancer Foundation, Grant [PG-08-01]. Bettina Meiser is supported by a Career Development Award Level 2 from the National Health and Medical Research Council of Australia and a Career Development Fellowship from the Cancer Institute New South Wales. The authors would like to thank the study participants, as well as the genetic counsellors at the Familial Cancer Centres at Monash Medical Centre, Peter MacCallum Cancer Centre, Prince of Wales Hospital, Westmead Hospital, the Royal Melbourne Hospital, and South Australia Clinical Genetics Service. The authors would also like to acknowledge the work of Ms Jane Hayman on this research project.

Role of funding: No funding source had any role in the design; collection, analysis and interpretation of data for this study; or in the writing of the report and decision to submit the paper for publication. The authors declare that they have no conflict of interest. 


\section{References}

1. Antoniou A, Pharoah PD, Narod S, Risch HA, Eyfjord JE, Hopper JL, Loman N, Olsson H, Johannsson O, Borg A, Pasini B, Radice P, Manoukian S, Eccles DM, Tang N, Olah E, Anton-Culver H, Warner E, Lubinski J, Gronwald J, Gorski B, Tulinius H, Thorlacius S, Eerola H, Nevanlinna H, Syrjakoski K, Kallioniemi OP, Thompson D, Evans C, Peto J, Lalloo F, Evans DG, Easton DF (2003) Average risks of breast and ovarian cancer associated with BRCA1 or BRCA2 mutations detected in case series unselected for family history: a combined analysis of 22 studies. Am J Hum Genet 72 (5):1117-1130. doi:10.1086/375033

2. Rebbeck TR, Friebel T, Lynch HT, Neuhausen SL, van 't Veer L, Garber JE, Evans GR, Narod SA, Isaacs C, Matloff E, Daly MB, Olopade OO, Weber BL (2004) Bilateral prophylactic mastectomy reduces breast cancer risk in BRCA1 and BRCA2 mutation barriers: the PROSE Study Group. J Clin Oncol 22 (6):1055-1062

3. Rebbeck TR, Lynch HT, Neuhausen SL, Narod SA, van 't Veer L, Garber JE, Evans GR, Isaacs C, Daly MB, Matloff E, Olopade OO, Weber BL (2002) Prophylactic oophorectomy in carriers of BRCA1 or BRCA2 mutations. N Engl J Med 346 (21):1616-1622

4. Clarke-Pearson DL (2009) Screening for ovarian cancer. N Engl J Med 361:170-177

5. Youlden DR, Cramb SM, Dunn NAM, Muller JM, Pyke CM, Baade PD (2012) The descriptive epidemiology of female breast cancer: an international comparison of screening, incidence, survival and mortality. Cancer Epidemiol 36 (3):237-248

6. Kriege M, Brekelmans C, Boetes C, Besnard P, Zonderland H, Obdeijn I, Manoliu R, Kok T, Peterse H, Tilanus-Linthorst M, Muller SH, Meijer S, Oosterwijk JC, Beex L, Tollenaar R, de Koning H, Rutgers E, Klijn JGM (2004) Efficacy of MRI and mammography for breast-cancer screening in women with a familial or genetic predisposition. N Engl J Med 351 (5):427-437 
7. Meiser B, Butow P, Friedlander M, Barratt A, Schnieden V, Watson M, Brown J, Tucker K (2002) Psychological impact of genetic testing in women from high-risk breast cancer families. Euro J Cancer 38:2025-2033

8. Croyle R, Smith K, Botkin J, Baty B, Nash J (1997) Psychological responses to BRCA1 mutation testing: preliminary findings. Health Psychol 16:63-72

9. Braithwaite D, Emery J, Walter F, Prevost AT, Sutton S (2004) Psychological impact of genetic counseling for familial cancer: a systematic review and meta-analysis. J Natl Cancer Inst 96:122-123

10. Meiser B (2005) Psychological impact of genetic testing for cancer susceptibility: an update of the literature. Psychooncology 14 (12):1060-1074. doi:10.1002/pon.933

11. Tjemsland L, Soreide J, Malt U (1998) Posttraumatic distress symptoms in operable breast cancer III: status one year after surgery. Breast Cancer Res Treat 47:141-151

12. Lindberg NM, Wellisch DK (2004) Identification of traumatic stress reactions in women at increased risk for breast cancer. Psychosomatics 45:7-16

13. van Oostrom I, Meijers-Heijboer H, Lodder LN, Duivenvoorden HJ, van Gool AR, Seynaeve C, van der Meer CA, Klijn JGM, van Geel BN, Burger CW, Wladimiroff JW, Tibben A (2004) Long-term psychological impact of carrying a BRCA1/2 mutation and prophylactic surgery: A 5-year follow-up study. J Clin Oncol 21:3867-3874

14. Hodgkinson K, Butow P, Hunt GE (2007) Breast cancer survivors' supportive care needs 2-10 years after diagnosis. Support Care Cancer 15 (5):515-523

15. Harrison JD, Young JM, Price MA, Butow PN, Solomon MJ (2009) What are the unmet supportive care needs of people with cancer? A systematic review. Support Care Cancer 17:1117-1128

16. Thewes B, Meiser B, Tucker M, Tucker K (2003) The unmet information and support needs of women with a family history of breast cancer: a descriptive survey. J Genetic Counselling $12(1): 61-76$ 
17. Iredale R, Brain K, Edwards L, Gray J, France E (2003) The information and support needs of women at high risk of familial breast and ovarian cancer: how can cancer genetic services give patients what they want? Fam Cancer 2:119-121

18. Werner-Lin A (2008) Formal and informal support needs of young women with BRCA mutations. J Psychosoc Oncol 26 (4):111-133

19. Beckmann K, Tait C, McCormack J, Suthers G (2004) Information and support needs of people with genetic errors associated with increased cancer risk: Summary report of study findings. SA Clinical Genetics Service and The Cancer Council South Australia.

20. Metcalfe KA, Liede A, Hoodfar E, Scott A, Foulkes WD, Narod SA (2000) An evaluation of needs of female BRCA1 and BRCA2 carriers undergoing genetic counselling. J Med Genet 37:866-874

21. Mor V, Allen SM, Siegel K, Houts P (1992) Determinants of needs and unmet need among cancer patients residing at home. Health Serv Res 27:337-360

22. Schmid-Buchi S, Halfens RJG, Muller M, Dassen T, van den Borne B (2012 [Epub ahead of print]) Factors associated with supportive care needs of patients under treatment for breast cancer. Eur J Oncol Nurs

23. Butow PN, Phillips F, Schweder J, White K, Underhill C, Goldstein D (2011)

Psychosocial well-being and supportive care needs of cancer patients living in urban and rural/regional areas: a systematic review. Support Care Cancer 20 (1):1-22

24. Sanson-Fisher R, Girgis A, Boyes A, Bonevski B, Burton L, Cook P (2000) The unmet supportive care needs of patients with cancer. Cancer 88 (1):226-237

25. Fatouros M, Baltoyiannis G, Roukos DH (2007) The predominant role of surgery in the prevention and new trends in the surgical treatment of women with BRCA1/2 mutations. Ann Surg Oncol 15 (1):21-33

26. Bonevski B, Sanson-Fisher R, Girgis A, Burton L, Cook P, Boyes A (2000) Evaluation of an instrument to assess the needs of patients with cancer. Supportive Care Review Group. Cancer 88 (1):217-225 
27. Foot G, Sanson-Fisher R (1995) Measuring the unmet needs of people living with cancer. Cancer Forum 19 (2):131-135

28. Horowitz M, Wilner N, Alvarez W (1979) Impact of event scale: a measure of subjective stress. Psychosom Med 41:209-218

29. Horowitz M (2006) Impact of Events Scale. http://www.mardihorowitz.com/impact of events scale. 2011

30. Finch A, Metcalfe KA, Chiang J, Elit L, McLaughlin J, Springate C, Esplen MJ, Demsky R, Murphy J, Rosen B, Narod SA (2011 [Epub ahead of print]) The impact of prophylactic salpingo-oophorectomy on quality of life and psychological distress in women with a BRCA mutation. Psychooncology. doi:10.1002/pon.2041

31. Thewes B, Meiser B, Hickie IB (2001) Psychometric properties of the Impact of Event Scale amongst women at increased risk for hereditary breast cancer. Psychooncology $10(6): 459-468$

32. Froot KA (1989) Consistent covariance matrix estimation with cross-sectional dependence and heteroskedasticity in financial data. JFQA 24:333-355

33. Thewes B, Butow P, Girgis A, Pendlebury S (2004) The psychosocial needs of breast cancer survivors: a qualitative study of the shared and unique needs of younger versus older survivors. Psychooncology 13:177-189

34. Thewes B, Meiser B, Taylor A, Phillips KA, Capp PA, Dalley D, Goldstein D, Baber R, Friedlander ML (2005) Fertility and menopause related information needs of younger women with a diagnosis of early breast cancer. J Clin Oncol 23 (22):5155-5165

35. Hoey LM, leropoli SC, White VM, Jefford M (2008) Systematic review of peer-support programs for people with cancer. Patient Educ Couns 70 (3):315-337. doi:S07383991(07)00449-1

36. Ganz PA (2008) Psychological and social aspects of breast cancer. Oncology 22

(6):642-646 
37. Schwartz MD, Peshkin BN, Hughes C, Main D, Isaacs C, Lerman C (2002) Impact of BRCA1/BRCA2 mutation testing on psychologic distress in a clinic-based sample. J Clin Oncol 20 (2):514-520

38. Smith K, West J, Croyle R, Botkin JR (1999) Familial context of genetic testing for cancer susceptibility: moderating effect of siblings' test results on psychological distress one to two weeks after BRCA1 mutation testing. Cancer Epidemiol Biomarkers Prev 8:385392

39. den Heijer M, Seynaeve C, Vanheusden K, Duivenvoorden HJ, Bartels CCM, MenkePluymers MBE, Tibben A (2011) Psychological distress in women at risk for hereditary breast cancer: the role of family communication and perceived social support. Psychooncology 2:1317-1323

40. Hamilton R, Hurley KE (2010) Conditions and consequences of a BRCA mutation in young, single women of childbearing age. Oncol Nurs Forum 37 (5):627-634

41. Madalinska JB, Hollenstein J, Bleiker E, van Beurden M, Valdimarsdottir HB, Massuger LF, Katja N, Gaarenstroom KN, Mourits MJE, Verheijen RHM, van Dorst EBL, van der Putten H, van der Velden K, Boonstra H, Aaronson NK (2005) Quality of life effects of prophylactic salpingo-oophorectomy versus gynecologic screening among women at increased risk of hereditary ovarian cancer. J Clin Oncol 23 (28):6890-6898

42. Bresser PJC, Seynaeve C, Van Gool AR, Niermeijer MF, Duivenvoorden HJ, van Dooren S, van Geel AN, Menke-Pluijmers M, Klijn JGM, Tibben A (2007) The course of distress in women at increased risk of breast and ovarian cancer due to an (identified) genetic susceptibility who opt for prophylactic mastectomy and/or salpingo oophorectomy. Euro J Cancer 43:95-103 
Table 1: Demographic, marital, cancer history and risk-reducing surgery characteristics of participants along with unmet needs and distress.

\begin{tabular}{|c|c|c|c|c|c|}
\hline Variable & $\%(n)$ & $\mathbf{N}$ & $\begin{array}{l}\text { Unmet Needs }^{1} \\
\text { Mean (SD) }\end{array}$ & \multicolumn{2}{|c|}{$\begin{array}{l}\text { Moderate to Severe } \\
\text { Distress } \\
\%(n)\end{array}$} \\
\hline $\begin{array}{l}\text { Children } \\
\text { Yes } \\
\text { No }\end{array}$ & $\begin{array}{c}81.4(227) \\
18.6(52)\end{array}$ & 279 & $\begin{array}{c}9.0(5.6) \\
10.2(4.1)\end{array}$ & \multicolumn{2}{|c|}{$\begin{array}{l}32.4(72) \\
39.2(20)\end{array}$} \\
\hline $\begin{array}{l}\text { Marital Status } \\
\text { Married } \\
\text { In a relationship (but not married) } \\
\text { Single/Divorced/Widowed }\end{array}$ & $\begin{array}{l}67.6(188) \\
15.1(42) \\
17.3(48)\end{array}$ & 278 & $\begin{array}{l}8.9(5.4) \\
10.9(4.6) \\
9.3(5.6)\end{array}$ & \multicolumn{2}{|c|}{$\begin{array}{l}28.7(54) \\
61.9(26) \\
25.5(12)\end{array}$} \\
\hline $\begin{array}{l}\text { Education level } \\
\quad \text { No post-secondary } \\
\text { Post-secondary }\end{array}$ & $\begin{array}{l}35.6(99) \\
64.4(179)\end{array}$ & 278 & $\begin{array}{l}9.0(5.7) \\
9.4(5.2)\end{array}$ & \multicolumn{2}{|c|}{$\begin{array}{l}28.4(27) \\
36.2(64)\end{array}$} \\
\hline $\begin{array}{l}\text { Previous diagnosis of breast or ovarian cancer } \\
\qquad \begin{array}{ll}\text { No } & \\
\text { Yes } & \\
& \text { Breast } \\
& \text { Ovarian } \\
& \text { Both breast and ovarian cancer }\end{array}\end{array}$ & $\begin{array}{c}55.2(153) \\
44.8(124) \\
37.2(103) \\
6.1(17) \\
1.4(4)\end{array}$ & 277 & $\begin{array}{l}9.4(5.3) \\
9.2(5.4)\end{array}$ & \multicolumn{2}{|c|}{$\begin{array}{l}30.9(47) \\
36.7(44)\end{array}$} \\
\hline $\begin{array}{l}\text { History of risk-reducing surgery } \\
\text { Both Surgeries } \\
\text { Bilateral salpingo-oophorectomy (BSO) only } \\
\text { Bilateral mastectomy (BM) only } \\
\text { No surgery }\end{array}$ & $\begin{array}{c}21.2(58) \\
33.9(93) \\
8.0(22) \\
36.9(101)\end{array}$ & 274 & $\begin{array}{c}9.0(5.3) \\
8.9(5.9) \\
10.1(4.5) \\
9.6(4.9)\end{array}$ & \multicolumn{2}{|c|}{$\begin{array}{l}33.3(18) \\
22.8(21) \\
54.5(12) \\
40.6(41)\end{array}$} \\
\hline $\begin{array}{l}\text { Have someone to confide in about mutation } \\
\text { status } \\
\quad \text { Yes } \\
\text { No }\end{array}$ & $\begin{array}{l}92.8(258) \\
7.2(20)\end{array}$ & 278 & $\begin{array}{l}9.1(5.3) \\
11.7(5.2)\end{array}$ & \multicolumn{2}{|c|}{$\begin{array}{l}31.6(80) \\
63.2(12)\end{array}$} \\
\hline & & & & \multicolumn{2}{|c|}{ Mean (S.D) } \\
\hline & & & Correlation & $\begin{array}{l}\text { Low } \\
\text { Distress }\end{array}$ & $\begin{array}{l}\text { Mod-Severe } \\
\text { Distress }\end{array}$ \\
\hline Age (mean 46.3 years, $S D=13.9$, range $19-83$ ) & - & 279 & -0.18 & $47.8(14.2)$ & $42.3(11.9)$ \\
\hline $\begin{array}{l}\text { Number of first and second degree relatives } \\
\text { diagnosed with breast and/or ovarian cancer } \\
\text { (mean } 3.1, S D=2.1 \text { ) }\end{array}$ & - & 272 & 0.04 & $3.1(2.2)$ & $3.1(2.0)$ \\
\hline $\begin{array}{l}\text { Time since notification of mutation status (mean } \\
1.7 \text { years, } S D=1.5 \text { ) }\end{array}$ & - & 276 & -0.14 & $1.8(1.5)$ & $1.5(1.4)$ \\
\hline Number of unmet needs ${ }^{1}$ (mean 9.2, SD=1.3) & - & 276 & - & $7.9(5.4)$ & $12.0(4.0)$ \\
\hline
\end{tabular}

${ }^{1}$ Sum number of low to very high unmet needs. 
Table 2: Distribution of participant's responses to unmet needs items $(n=279)$

\begin{tabular}{|l|c|c|c|c|}
\hline Item & $\begin{array}{c}\text { No Need } \\
\%(\mathbf{n})\end{array}$ & $\begin{array}{c}\text { Low } \\
\%(\mathbf{n})\end{array}$ & $\begin{array}{c}\text { Moderate } \\
\%(\mathbf{n})\end{array}$ & $\begin{array}{c}\text { High to } \\
\text { Very High } \\
\mathbf{n})\end{array}$ \\
\hline $\begin{array}{l}\text { Obtaining more information about your level of } \\
\text { risk for breast cancer }\end{array}$ & $46.4(128)$ & $23.9(66)$ & $18.1(50)$ & $11.6(32)$ \\
\hline $\begin{array}{l}\text { Dealing with the impact that having a faulty gene } \\
\text { has had on your family }\end{array}$ & $32.2(89)$ & $26.4(73)$ & $27.9(77)$ & $13.4(37)$ \\
\hline Dealing with feelings of sadness & $33.6(93)$ & $29.6(82)$ & $23.1(64)$ & $13.8(38)$ \\
\hline Dealing with uncertainty about the future & $29.5(81)$ & $24.4(67)$ & $28.4(78)$ & $17.8(49)$ \\
\hline $\begin{array}{l}\text { Talking to other family members about having a } \\
\text { faulty cancer protection gene }\end{array}$ & $34.1(94)$ & $28.6(79)$ & $17.8(49)$ & $19.6(54)$ \\
\hline Dealing with fears about developing cancer & $29.1(81)$ & $28.4(79)$ & $21.9(61)$ & $20.5(57)$ \\
\hline $\begin{array}{l}\text { Reassurance that the way you feel about your } \\
\text { risk is normal }\end{array}$ & $40.8(113)$ & $30.3(84)$ & $16.2(45)$ & $12.7(35)$ \\
\hline $\begin{array}{l}\text { Dealing with the loss of family members who had } \\
\text { breast cancer }\end{array}$ & $50.5(140)$ & $22.0(61)$ & $15.2(42)$ & $12.3(34)$ \\
\hline $\begin{array}{l}\text { Understanding the information you have been } \\
\text { given about your cancer risk }\end{array}$ & $47.8(133)$ & $23.0(64)$ & $17.6(49)$ & $11.5(32)$ \\
\hline $\begin{array}{l}\text { Talking with other women who have a faulty } \\
\text { cancer protection gene }\end{array}$ & $37.4(104)$ & $26.6(74)$ & $21.2(59)$ & $14.8(41)$ \\
\hline $\begin{array}{l}\text { Talking to your children about their cancer risk (of } \\
\text { women with children, } n=198)\end{array}$ & $53.5(145)$ & $17.7(48)$ & $10.7(29)$ & $18.1(49)$ \\
\hline $\begin{array}{l}\text { Deciding how best to manage your increased } \\
\text { cancer risk }\end{array}$ & $37.9(105)$ & $22.4(62)$ & $24.2(67)$ & $15.5(43)$ \\
\hline $\begin{array}{l}\text { Obtaining information about the different options } \\
\text { available to help manage your increased risk for } \\
\text { cancer }\end{array}$ & $43.1(119)$ & $22.1(61)$ & $16.3(45)$ & $18.4(51)$ \\
\hline Dealing with feelings of isolation & $50.4(139)$ & $27.2(75)$ & $14.5(40)$ & $7.9(22)$ \\
\hline Finding someone who understands your situation & $41.5(115)$ & $23.5(65)$ & $20.9(58)$ & $14.1(39)$ \\
\hline $\begin{array}{l}\text { Dealing with insurance issues that arise from } \\
\text { having a faulty cancer protection gene }\end{array}$ & $60.9(167)$ & $16.8(46)$ & $13.9(38)$ & $8.4(23)$ \\
\hline
\end{tabular}


Table 3: Univariate and multivariable associations of independent variables with summed number of any unmet needs (low to very high)

\begin{tabular}{|c|c|c|c|c|c|c|c|}
\hline \multirow[b]{2}{*}{ Variable } & \multicolumn{4}{|c|}{ Univariate Analyses } & \multicolumn{3}{|c|}{ Multivariable Analyses (full model) } \\
\hline & $\mathbf{N}$ & B (SE) & $\mathbf{t}$ & $p$ value & B (SE) & $\mathbf{t}$ & $\mathrm{p}$ value \\
\hline \multicolumn{8}{|l|}{ Cancer diagnosis } \\
\hline Yes & 122 & $-0.21(0.62)$ & -0.33 & 0.74 & $0.67(0.74)$ & 0.91 & 0.36 \\
\hline No & 153 & & & & & & \\
\hline \multicolumn{8}{|l|}{ Risk-reducing surgery } \\
\hline $\mathrm{BSO}$ & 93 & Ref & & & Ref & & \\
\hline BM & 22 & $1.16(1.15)$ & 1.01 & 0.32 & $-0.30(1.23)$ & -0.24 & 0.81 \\
\hline Both surgeries & 55 & $0.01(0.96)$ & 0.01 & 0.99 & $-0.25(1.01)$ & -0.25 & 0.80 \\
\hline No surgery & 101 & $0.64(0.81)$ & 0.79 & 0.43 & $-0.74(0.84)$ & -0.88 & 0.38 \\
\hline \multicolumn{8}{|l|}{ Children } \\
\hline Yes & 225 & $-1.22(0.70)$ & -1.76 & 0.08 & $0.60(0.95)$ & 0.62 & 0.53 \\
\hline No & 51 & & & & & & \\
\hline \multicolumn{8}{|l|}{ Education level } \\
\hline $\begin{array}{l}\text { Secondary school or } \\
\text { less }\end{array}$ & 98 & $-0.38(0.65)$ & -0.58 & 0.56 & $0.61(0.72)$ & 0.85 & 0.40 \\
\hline Post-secondary & 177 & & & & & & \\
\hline \multicolumn{8}{|l|}{ Marital status } \\
\hline Married & 185 & Ref & & & Ref & & \\
\hline In a relationship & 42 & $2.00(0.81)$ & 2.47 & 0.01 & $1.22(0.90)$ & 1.35 & 0.18 \\
\hline Single/Divorced/Widowed & 48 & $0.46(0.89)$ & 0.52 & 0.61 & $-0.12(0.95)$ & -0.17 & 0.87 \\
\hline \multicolumn{8}{|l|}{$\begin{array}{l}\text { Has someone to confide in } \\
\text { about gene status }\end{array}$} \\
\hline Yes & 256 & $2.59(1.20)$ & 2.16 & 0.03 & $2.92(1.14)$ & 2.57 & 0.01 \\
\hline \multirow[t]{2}{*}{ No } & 19 & & & & & & \\
\hline & $\mathbf{N}$ & & & & & & \\
\hline Age & 276 & $-0.07(0.02)$ & -3.04 & $<0.01$ & $-0.11(0.03)$ & -3.34 & $<0.01$ \\
\hline $\begin{array}{l}\text { Time since notification of } \\
\text { mutation status }\end{array}$ & 276 & $-0.48(0.22)$ & -2.21 & 0.03 & $-0.60(0.24)$ & -2.49 & 0.01 \\
\hline $\begin{array}{l}\text { Number of first/second } \\
\text { degree relatives diagnosed } \\
\text { with breast and/or ovarian } \\
\text { cancer. }\end{array}$ & 269 & $0.09(0.17)$ & 0.53 & 0.60 & $0.30(1.66)$ & 1.82 & 0.07 \\
\hline $\begin{array}{l}R^{2}=0.10 \\
F(12,211)=2.77, p<0.01\end{array}$ & & & & & & & \\
\hline
\end{tabular}


Table 4: Univariate and multivariable associations of independent variables with moderate to severe test-related distress (IES)

\begin{tabular}{|c|c|c|c|c|c|}
\hline \multirow[b]{2}{*}{ Variable } & \multirow[b]{2}{*}{$\mathbf{N}$} & \multicolumn{2}{|c|}{ Univariate Analyses } & \multicolumn{2}{|c|}{$\begin{array}{l}\text { Multivariable Analyses } \\
\text { (full model) }\end{array}$} \\
\hline & & OR (95\% Cl) & $P$ value & OR (95\% Cl) & $P$ value \\
\hline \multicolumn{6}{|l|}{ Cancer Diagnosis } \\
\hline Yes & 114 & $1.29(0.76,2.20)$ & 0.34 & $1.72(0.74,4.00)$ & 0.21 \\
\hline No & 150 & & & & \\
\hline \multicolumn{6}{|l|}{ Risk-reducing Surgery } \\
\hline $\mathrm{BSO}$ & 92 & 1.00 & & 1.00 & \\
\hline BM & 22 & $4.06(1.57,10.51)$ & $<0.01$ & $4.78(1.49,15.32)$ & $<0.01$ \\
\hline Both surgeries & 54 & $1.69(0.78,3.68)$ & 0.19 & $1.75(0.66,4.63)$ & 0.26 \\
\hline No surgery & 101 & $2.31(1.27,4.22)$ & $<0.01$ & $2.48(1.11,5.51)$ & 0.03 \\
\hline \multicolumn{6}{|l|}{ Children } \\
\hline Yes & 222 & $0.74(0.40,1.40)$ & 0.36 & $1.94(0.76,4.91)$ & 0.16 \\
\hline No & 51 & & & & \\
\hline \multicolumn{6}{|l|}{ Education level } \\
\hline Secondary school or less & 94 & $0.70(0.41,1.20)$ & 0.19 & $0.70(0.35,1.42)$ & 0.33 \\
\hline Post-secondary & 171 & & & & \\
\hline \multicolumn{6}{|l|}{ Marital Status } \\
\hline Married & 188 & 1.00 & & 1.00 & \\
\hline $\begin{array}{l}\text { In a relationship (but not } \\
\text { married) }\end{array}$ & 42 & $3.88(1.94,7.78)$ & $<0.01$ & $4.14(1.70,10.16)$ & $<0.01$ \\
\hline Single/Divorced/Widowed & 47 & $0.82(0.40,1.67)$ & 0.58 & $0.55(0.23,1.29)$ & 0.17 \\
\hline \multicolumn{6}{|l|}{$\begin{array}{l}\text { Has someone to confide in } \\
\text { about having the BRCA } \\
\text { mutation }\end{array}$} \\
\hline No & 19 & $3.71(1.38,9.94)$ & $<0.01$ & $5.17(1.51,17.75)$ & 0.01 \\
\hline Yes & 253 & & & & \\
\hline Age & 273 & $0.97(0.95,0.99)$ & $<0.01$ & $0.99(0.96,1.02)$ & 0.46 \\
\hline Time since notification & 273 & $0.88(0.73,1.06)$ & 0.18 & $0.94(0.73,1.21)$ & 0.66 \\
\hline Number of unmet needs ${ }^{1}$ & 272 & $1.18(1.12,1.25)$ & $<0.01$ & $1.19(1.11,1.27)$ & $<0.01$ \\
\hline $\begin{array}{l}\text { Number of first/second degree } \\
\text { relatives diagnosed with cancer }\end{array}$ & 266 & $0.99(0.88,1.10)$ & 0.83 & $1.07(0.91,1.25)$ & 0.40 \\
\hline
\end{tabular}

${ }^{1}$ Sum number of low to very high unmet needs. 